\title{
THE EXTENT OF MEDICINE WASTAGES IN A TERTIARY HOSPITAL IN BRUNEI: 10 YEARS' RETROSPECTIVE STUDY FROM 2006 TO 2016
}

\author{
NUROLAINI KIFLI ${ }^{1 *}$, WONG WAI SEE ${ }^{2}$, LI LING CHAW ${ }^{1}$ \\ ${ }^{1}$ PAPRSB Institute of Health Science Universiti Brunei Darussalam, Seri Begawan, Brunei. ${ }^{2}$ Department of Pharmaceutical Services, \\ Ministry of Health, Brunei Darussalam, Seri Begawan, Brunei. Email: nurolaini.kifli@ubd.edu.bn
}

Received: 16 January 2018, Revised and Accepted: 13 April 2018

\section{ABSTRACT}

Objective: Access to health and medical care for Bruneians is at a negligible cost. Medication wastage poses a financial burden on the nation's economy. This retrospective study aims to measure the extent of medicines wastage in a tertiary hospital in Brunei Darussalam and its relation to the costs.

Methods: The collected dataset records all information on returned medicines to the inpatient pharmacy in Raja Isteri Pengiran Anak Saleha hospital from 2006 to 2016. This information includes the dates and location from where medication is returned, its form, its unit price, and its status after being returned. The datum was analyzed using R statistical software (version 3.3).

Results: A total of 1,290,254 units of medications were returned, totaling BND $\$ 3,703,170$. These medications were returned from hospital wards $(88.5 \%)$, inpatient pharmacy (34.3\%), and health centers $(2.7 \%)$. The majority of returned medications were in an oral solid form (78.5\%), followed by injections (13.7\%) and topical preparations (3.2\%). Among the recorded medications, 53.8\% were eventually reused (a total of BND $\$ 1,177,147$ ) and $38.3 \%$ were disposed (a total of BND \$1,538,022). Oral solids formed the majority of both the reused (89.7\%) and disposed (74.7\%) medications. $60.2 \%$ of the medications returned by the hospital wards were reused.

Conclusion: Medication recycling and wastage exist in Brunei. Health-care policymakers should be informed to implement wastage reduction strategies. One major limitation is the amount of missing data and the consistency of data entry. The eventual destinations of $7.8 \%$ of the returned medications were unrecorded and 879 entries (1.4\%) were removed from the analysis, after applying the exclusion criteria and also to account for suspected data entry errors.

Keywords: Medication wastage, Tertiary hospital, Returned medicines, Brunei Darussalam.

(C) 2018 The Authors. Published by Innovare Academic Sciences Pvt Ltd. This is an open access article under the CC BY license (http://creativecommons. org/licenses/by/4. 0/) DOI: http://dx.doi.org/10.22159/ajpcr.2018.v11i7.24789

\section{INTRODUCTION}

According to a team of experts defined by the Delphi technique, medication wastage is the unnecessary consumption of medications by patients or the unjustified non-adherence to treatment guidelines by health-care professionals. It also refers to any medication, which expires or remains unused throughout the whole medicine supply chain [1]. In this paper, we are referring to the terminology of medication wastage as to medicines which expire or remain unused throughout the whole medicine supply chain.

The extent of medication wastage has been studied by various groups, with quantities ranging from 65 unused medication items gathered from 73 households [2] to 20,304 medications packages collected from 100 community pharmacies [3]. Medication wastage poses a financial burden on the nation's economy, as well as environmental implications associated with its disposal [4]. Diverse classes of pharmaceutical compounds like analgesic, antidepressant, antihypertensive, contraceptive, antibiotic, steroids and hormones have been detected in water samples from $\mathrm{ng} / \mathrm{l}$ to $\mu \mathrm{g} / \mathrm{l}$ range; although in small quantity, it can be highly toxic to human, animal, and aquatic lives. According to the review paper, there is a need for regular monitoring of the concentration of pharmaceutical compounds in pharmaceutical effluents entering into drinking water sources to save environment as well as living form of lives from health hazards [5]. The World Health Organization reported a total of $0.2-0.5 \mathrm{~kg}$ of waste being generated per hospital bed per day, of which $3 \%$ was attributable to drug wastage [6]. In 2009, a study conducted by the Department of Health in the United Kingdom explored the scale and cost of medication wastage, and they concluded that direct costs of unused prescription medication to the National
Health Service amounted to $£ 300$ million annually [7].

Brunei Darussalam has a universal health-care system whereby the services and funding were provided mainly by the government. Bruneian citizens pay a very minimal amount for their health-care services when treated in public hospital or health centers. The total health expenditures by Brunei's Government for the whole country have increased $3.5 \%$ recently from BND \$ 389.3 million in 2013/14 to BND \$ 403.27 million in 2015/16 [8]. Thus, medication wastage would have financial implications for the government.

Pharmacy teams can contribute to managing drug spending by reducing medicine wastage. In 2006, the Department of Pharmaceutical Services, Ministry of Health Brunei (MOH), has implemented the "return your medicines" program whereby, patients, either from home or in the wards, can return their unused medicines to their nearest hospitals or health centers for safe disposal or recycling. The medicines being disposed or recycled will be evaluated and assessed using a set of protocol (Table 1).

This "return your medicines" program has also been implemented among the doctors and health-care professionals within the hospitals and health centers. Similar programs are being implemented in Malaysia. According to the Ministry of Health, Malaysia, there are various factors contributing toward the excessive medicines storage, among them are patients died; non-adherence to their medications; and change or cessation of treatment regimen and polypharmacy [9]. In another study, it has been shown that patients were afraid that their medications will be unavailable when they need them, and consequently, they tend to stock up on their medications [10]. In an 
Indian state (among the slum dweller), there is a high prevalence of self-medication (47\%) and they tend to procure and store medicines for minor illness at home for future use in emergencies. A majority (76\%) of them were also ignorant about the expiry date of the medicines [11]. Medication wastage thus compromises public health in terms of safety and the environment, poor health outcomes from non-adherence, and anti-microbial/anti-viral resistance when courses of such types of medicines are not completed.

As to our knowledge, there has been no study conducted to explore the scale of the medicine wastage in the largest tertiary hospital in Brunei Darussalam: Raja Isteri Pengiran Anak Saleha (RIPAS) hospital. This is a 10-year retrospective study (2006-2016), with data obtained from the Department of Pharmaceutical Services, Ministry of Health with the aim to explore the extent of medicines wastage and recycling pattern in relation to its associated costs.

The objectives of the study are as follows: (1) To assess the actual cost savings from recycling the returned medicines from the year 2006 to 2016 in RIPAS hospital, (2) to identify the sources of donor for the medicines returned to inpatient pharmacy in RIPAS hospital, (3) to identify the types of medicines (formulation) being returned and being recycled in the set protocol, and (4) to assess ways on how pharmacists can help mitigate medicines wastages.

\section{MATERIALS AND METHODS}

The data collection site for this study is RIPAS hospital, the main referral government hospital in Brunei Darussalam and located at the capital city. It offers a very wide and comprehensive range of medical and surgical services covering almost 30 different specialties and subspecialties. In 2016, RIPAS hospital has increased to 772 beds with an occupancy rate of $61 \%$ in which they have an average of 474 inpatients per day [8]. Permission to access the secondary data was granted from the Acting Director of Pharmaceutical Services Department, Ministry of Health on $8^{\text {th }}$ December 2016 (Ref: (2) DPS/UBD/2016). Ethical approval was also granted by the Medical and Health Research Ethics Committee (MHREC) from the Ministry of Health, Brunei Darussalam dated 11 November 2017 (Ref: MHREC/EDU/2017/8/1(2)).

\section{Data collection}

The collected dataset records all information on returned medicines to the inpatient pharmacy in RIPAS hospital from January 2006 to December 2016, using a predesigned data recording form in Microsoft Access. No sample size calculation is required as all recorded medications were included in this study. This data recording is in line with the standard operating procedure for the inpatient pharmacy department (Appendix 1).

The recorded information includes (1) name of medication (Brand or Generic), (2) product formulation of medication, (3) origin of returned medications, (4) date received (month and year), (5) quantity received, (6) unit price, (7) status of returned medication (either disposed, reused, or others), and (8) expiry date.

Each drug was counted as one dosage unit regardless of dosage form (e.g., tablet, capsule, or syrup). Pricing of medication was obtained from the drug purchasing list used in the Ministry of Health Brunei Darussalam for that specific year. Potential wastage costs were calculated based on the price of the returned medicines which were disposed according to the set protocol (Table 1). Cost savings were calculated based on the total price of returned medicines which were eligible to be reused according to the set protocol (Table 1).

\section{Inclusion and exclusion criteria}

The inclusion criteria for this study were all recorded medications that were returned to the inpatient pharmacy of RIPAS hospital between 2006 and 2016. The exclusion criteria were (1) all medications that were recorded as returned from other district hospitals, (2) medications where the cost was not recorded, and (3) medications where the quantity received was wrongly recorded, as determined by a senior pharmacist.

\section{Definitions for the terms used}

The product formulation of the medicines being returned was defined based on the established criteria for sorting the returned medicines (Table 1). As this criterion did not include suppositories and implants, we decided to include both as separate categories, i.e., oral liquids, oral solids, injections, topical preparations, nasal and eye preparations, suppositories, and implants.

The location from where the medications were returned was classified into five categories: Health-care center, ward, inpatient pharmacy, others, and unrecorded. The others category include locations where medications were dispatched for other/specialized reasons, for example, National Heart Institute (IJN), blood bank, home-based nursing, manufacturing unit from the department of pharmacy, paramedics, and others, while the unrecorded category includes those where the location was not recorded.

The status of the returned medication was classified into four categories: Disposed, Reused, others, and unrecorded. Medications were defined as reused if the drugs were explicitly remarked as for reuse. In this study, medications were disposed if the medicines have one of the following criteria: (1) expired medicines, (2) medicines there was break in the cold-chain, (3) medicines improperly stored, (4) damaged medicines, (5) medicines were pre-packed item from a big container to a small packing (6) medicines listed on Named-Patient Basis (NPB) drugs and (7) medicines that were returned from either patients for disposal, emergency trolley stocks or major disaster/emergency cupboard. Medications were defined as others if they were remarked as either as oncology drugs or as patient leftover or returned drugs and unrecorded if they were not recorded.

\section{Statistical analysis}

Descriptive analysis (sums and proportions) was done to determine the total and stratified medication units and costs. The Mann-Whitney test was done to compare the medians of the two groups. R statistical software (version 3.3) was used in all analyses.

\section{RESULTS}

Between the years 2006 and 2016, a total of 1,290,254 units of medications were recorded as being returned to the inpatient pharmacy, RIPAS hospital. Fig. 1 shows the annual trend of the total quantity of the medications being disposed, reused, missing, and others against the total costs of BND \$. Table 2 shows the breakdown of the status of returned medication for their recorded location from which they were returned. 53.8\% and $38.3 \%$ of the total units of medications returned were recorded as reused and disposed, respectively. Depending on the location, the percentage of returned medications being ultimately disposed varies between $29.8 \%$ and $56.2 \% .60 .2 \%$ of the medications returned by the hospital wards were reused. Overall, these medications were mainly returned from hospital wards (88.5\%), inpatient pharmacy (34.3\%), and health centers (2.7\%).

Table 3 shows the breakdown of the medication forms for overall and by their recorded status after being returned to inpatient pharmacy, RIPAS. The majority of returned medications were in an oral solid form (78.5\%), followed by injections (13.7\%) and topical preparations (3.2\%). Oral solids formed the majority of both the disposed (74.7\%) and reused $(89.7 \%)$ medications. From a total of BND \$3,703,170 worth of returned medications, BND \$1,538,021.6 (41.5\%), BND \$ 1,177,147.1 (31.8\%), BND \$24,204.6 (0.7\%), and BND \$ 963,523.4 (26.0\%) were, respectively, classified as disposed, reused, others, and unrecorded.

When comparing the median costs for medications that were disposed and reused, significant differences were detected for oral solids, topical preparations, injections, injections, and overall costs (Table 4). 
Table 1: Protocol used for segregating the returned medicines to be reused or disposed

\begin{tabular}{|c|c|c|c|c|c|c|c|c|}
\hline $\begin{array}{l}\text { Formulation } \\
\text { type }\end{array}$ & \multicolumn{4}{|c|}{ Criteria to reuse the returned medicines* } & \multicolumn{4}{|c|}{ Criteria to dispose the returned medicines } \\
\hline Oral solid & \multicolumn{4}{|c|}{ Blister pack drugs that have not expired } & \multicolumn{4}{|c|}{$\begin{array}{l}\text { Blister pack drugs where the expiry dates are not available and lose } \\
\text { pack drugs with or without valid expiry dates }\end{array}$} \\
\hline Oral liquids & \multicolumn{4}{|c|}{$\begin{array}{l}\text { Any unopened liquid in its original packaging and has } \\
\text { not expired }\end{array}$} & \multicolumn{4}{|c|}{$\begin{array}{l}\text { All excess oral liquid either replaced or in its original bottle with or } \\
\text { without valid expiry dates }\end{array}$} \\
\hline Injections & \multicolumn{4}{|c|}{$\begin{array}{l}\text { Unused injections which do not require cold chain } \\
\text { maintenance, with valid expiry dates } \\
\text { Unused injections which require cold chain } \\
\text { maintenance, with valid expiry dates that have been } \\
\text { immediately taken from the wards' pharmaceutical } \\
\text { grade refrigerator and transferred to the pharmacy }\end{array}$} & \multicolumn{4}{|c|}{$\begin{array}{l}\text { Unused injections which require cold chain maintenance, where this } \\
\text { chain has been broken for unknown duration and exposure to unknown } \\
\text { temperature } \\
\text { All injections which have expired or expiry date that is not clearly visible }\end{array}$} \\
\hline $\begin{array}{l}\text { Topical } \\
\text { preparations }\end{array}$ & \multicolumn{4}{|c|}{$\begin{array}{l}\text { Unopened packs of cream and ointment with valid } \\
\text { expiry date }\end{array}$} & \multicolumn{4}{|c|}{ All opened used packs of cream and ointment } \\
\hline $\begin{array}{l}\text { Inhalers, } \\
\text { nasal, or eye } \\
\text { preparations }\end{array}$ & \multicolumn{4}{|c|}{$\begin{array}{l}\text { Unopened products in original packaging with valid } \\
\text { expiry date }\end{array}$} & \multicolumn{4}{|c|}{ All opened and used products for patients } \\
\hline \multicolumn{9}{|c|}{ *All reused medicines must be in good condition, which means no change in color, no precipitation, or any sign that could signify product deterioration } \\
\hline \multirow{2}{*}{\multicolumn{2}{|c|}{ Medication status }} & Overall (\%) & \multicolumn{6}{|c|}{ Number of units received from } \\
\hline & & & Health Center (\%) & \multicolumn{2}{|c|}{ Hospital ward (\%) } & Inpatient pharmacy (\%) & Others (\%) & Unrecorded (\%) \\
\hline Disposed & & 23611 (38.3) & 491 (29.8) & \multicolumn{2}{|c|}{$20147(37.0)$} & $1145(54.3)$ & $1776(56.2)$ & $52(33.1)$ \\
\hline Reused & & 33110 (53.8) & $89(5.4)$ & \multicolumn{2}{|c|}{$32813(60.2)$} & $3(0.1)$ & $100(3.2)$ & 105 (66.9) \\
\hline Others & & $44(0.1)$ & $0(0.0)$ & \multicolumn{2}{|c|}{$16(0.03)$} & $28(1.3)$ & $0(0.0)$ & $0(0.0)$ \\
\hline Unrecorded & & 4807 (7.8) & $1068(64.8)$ & \multicolumn{2}{|l|}{$1520(2.8)$} & $934(44.3)$ & $1285(40.6)$ & $0(0.0)$ \\
\hline Total & & $61572(100)$ & $1648(100)$ & \multicolumn{2}{|c|}{$54496(100)$} & $2110(100)$ & $3161(100)$ & $157(100)$ \\
\hline
\end{tabular}

Table 3: The overall breakdown of the number of dosage units of the returned medicines and its costs recorded after being returned to inpatient pharmacy, RIPAS hospital

\begin{tabular}{|c|c|c|c|c|c|c|c|c|c|c|}
\hline \multirow{3}{*}{$\begin{array}{l}\text { Form of } \\
\text { medication }\end{array}$} & \multirow{2}{*}{\multicolumn{2}{|c|}{ Overall }} & \multicolumn{8}{|c|}{ Status of medication } \\
\hline & & & \multicolumn{2}{|l|}{ Disposed } & \multicolumn{2}{|l|}{ Reused } & \multicolumn{2}{|l|}{ Others } & \multicolumn{2}{|l|}{ Unrecorded } \\
\hline & $\begin{array}{l}\text { Number of } \\
\text { units }(\%)\end{array}$ & $\begin{array}{l}\text { Cost } \\
\text { (BND \$) }\end{array}$ & $\begin{array}{l}\text { Number of } \\
\text { units (\%) }\end{array}$ & $\begin{array}{l}\text { Cost } \\
\text { (BND \$) }\end{array}$ & $\begin{array}{l}\text { Number of } \\
\text { units (\%) }\end{array}$ & $\begin{array}{l}\text { Cost } \\
\text { (BND \$) }\end{array}$ & $\begin{array}{l}\text { Number of } \\
\text { units (\%) }\end{array}$ & $\begin{array}{l}\text { Cost } \\
\text { (BND \$) }\end{array}$ & $\begin{array}{l}\text { Number of } \\
\text { units (\%) }\end{array}$ & $\begin{array}{l}\text { Cost } \\
\text { (BND \$) }\end{array}$ \\
\hline Oral solids & $48353(78.5)$ & $1,411,779.0$ & $17629(74.7)$ & $451,631.0$ & 29696 (89.7) & $636,749.1$ & $26(59.1)$ & $6,965.1$ & $1002(20.8)$ & $316,433.7$ \\
\hline $\begin{array}{l}\text { Topical } \\
\text { preparations }\end{array}$ & $1948(3.2)$ & $105,200.0$ & $1317(5.6)$ & $30,639.9$ & $262(0.8)$ & $7,573.6$ & $1(2.3)$ & 1.5 & 368 (7.7) & $66,985.0$ \\
\hline Injections & $8430(13.7)$ & $1,714,100.0$ & $3108(13.2)$ & $753,819.9$ & $2421(7.3)$ & $436,647.5$ & $17(38.6)$ & $17,238.0$ & $2884(60.0)$ & $506,395.0$ \\
\hline Oral Liquids & $1409(2.3)$ & $375,937.0$ & $836(3.5)$ & $265,664.9$ & $365(1.1)$ & $82,536.1$ & $0(0.0)$ & 0.0 & $208(4.3)$ & $27,736.1$ \\
\hline Suppositories & $159(0.3)$ & $4,056.0$ & $62(0.3)$ & $2,272.5$ & $89(0.3)$ & 968.6 & $0(0.0)$ & 0.0 & $8(0.2)$ & 815.1 \\
\hline $\begin{array}{l}\text { Inhalers, } \\
\text { nasal, } \\
\text { and eye } \\
\text { preparations }\end{array}$ & $1272(2.1)$ & $91,824.0$ & $659(2.8)$ & $33,993.4$ & $277(0.8)$ & $12,672.2$ & $0(0.0)$ & 0.0 & $336(7.0)$ & $45,158.5$ \\
\hline Implants & $1(0.002)$ & 274.0 & $0(0.0)$ & 0.0 & $0(0.0)$ & 0.0 & $0(0.0)$ & 0.0 & $1(0.02)$ & 273.6 \\
\hline
\end{tabular}

RIPAS: Raja Isteri Pengiran Anak Saleha

Table 4: Comparison of median costs of disposed and reused medications by the form of medications

\begin{tabular}{|c|c|c|c|c|c|}
\hline \multirow[t]{2}{*}{ Form of medications } & \multicolumn{2}{|l|}{ Disposed } & \multicolumn{2}{|l|}{ Reused } & \multirow[t]{2}{*}{ p-value ${ }^{*}$} \\
\hline & Median cost (IQR) & Range of cost & Median cost (IQR) & Range of cost & \\
\hline Oral solids & $1.35(4.25)$ & $0.05-59673.6$ & $2.20(6.45)$ & $0.05-24870.0$ & $<0.001$ \\
\hline Injections & $19.6(79.1)$ & $0.05-85147.2$ & $45.0(127.6)$ & $0.08-10150.0$ & $<0.001$ \\
\hline Oral liquids & $7.34(30.9)$ & $0.01-47424.0$ & $9.6(29.75)$ & $0.08-21510.0$ & 0.055 \\
\hline Suppository & $4.5(17.6)$ & $0.15-755.5$ & $3.0(9.55)$ & $0.15-268.8$ & 0.17 \\
\hline Inhalers, nasal, and eye preparations & $13.50(35.15)$ & $0.35-2117.5$ & $17.30(46.7)$ & $1.35-1092.0$ & 0.06 \\
\hline Overall & $2.10(9)$ & $0.01-85147.2$ & $2.70(9.4)$ & $0.05-24870.0$ & $<0.001$ \\
\hline
\end{tabular}

*Wilcoxon signed-rank test results for whole dataset. Results were still significant even after removing outliers. *IQR: Interquartile range 


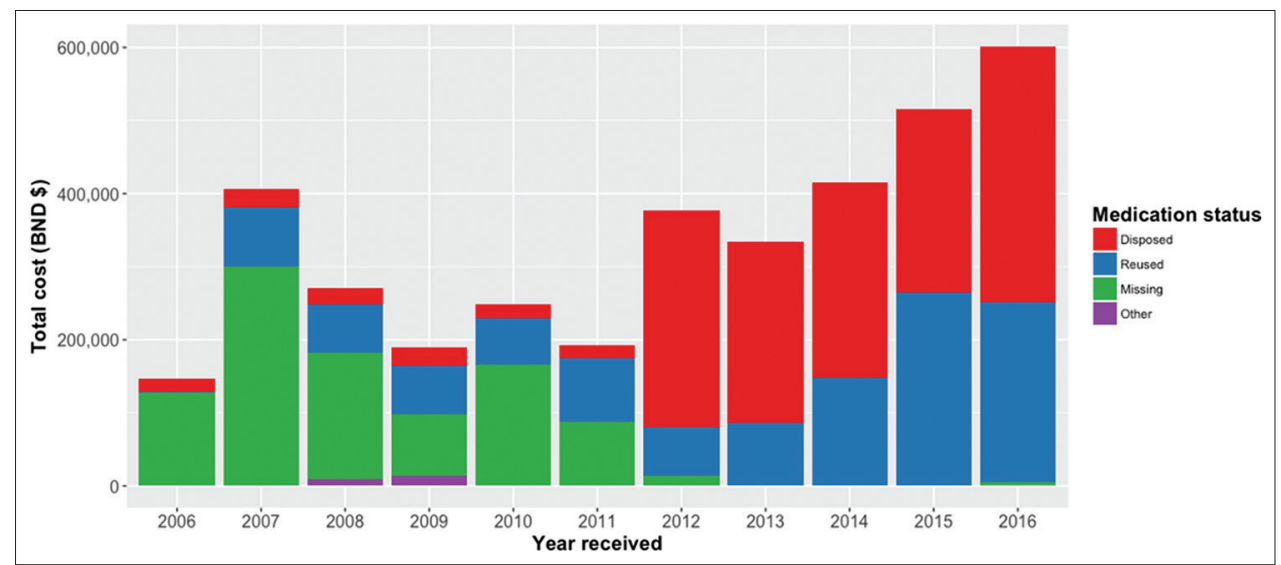

Fig. 1: The annual trend (2006-2016) of the total quantity of the medications being disposed, reused, missing, and others against the total costs

\section{DISCUSSIONS}

In a span of 10 years, a total of 1,290,254 units of medications were returned, totaling BND $\$ 3,703,170$. In Fig. 1, there is an increasing trend whereby the returned medicines have been reused in the hospital from the year 2012 to 2016. As shown in Table 2, the medications were mainly returned from hospital wards (88.5\%), inpatient pharmacy (34.3\%), and health centers (2.7\%). From 2014 to 2016, there is an increasing trend of returned medications that were recorded from the hospital wards. This is encouraging as probably there is an awareness among the doctors and health professionals as well as patients to implement the "return your medicine" program. This is further supported in Table 2, whereby $60.2 \%$ of the medicines being returned from the hospital wards were subsequently reused.

\section{Cost savings from the returned medicines}

We already knew that wastage from unused medications is a prevalent and costly issue. Health-care expenditure is rising throughout the developed world. In our study, we observed a substantial amount of cost savings during the 10 years' period, with a total of BND \$ 1,177,147 worth of medications being reused. A Singaporean study in 2014 evaluated the feasibility of medication recycling and assessed the actual cost savings from recycling returned medicines [12]. From that study, a total of 244 donations, be amounting to 20,759 dosage units, were collected during the 3 months' study period. Most donations (90.8\%) were reusable, providing a total of SGD $\$ 5,266$ in cost savings. In addition, we observed that most of the medicines that have been reused in this study are in the form of oral solids.

\section{Strategy to reduce medication wastage}

In Brunei Darussalam, since our medical and health-care bills are borne mostly by the government, reusing returned medicines is financially desirable and helps to optimize the use of medications. With proper checks, by the pharmacists for product integrity, medication recycling will be a useful strategy to reduce medicines wastage and government spending. In a study conducted in Karachi in 2014, medicines consumed the largest costs for diabetes mellitus[13]. It was also highlighted in the study that economic burden to the society could be reduced if rational drug use is implemented. In the 2012 action plan put forth by the Steering Group in the United Kingdom (UK) on improving the use of medicines, medication recycling was not considered due to concerns over the integrity of medicines among other practical, technical, and ethical factors which were not specified [14]. Of the 20,759 dosage units collected in that study, none was degraded and most were suitable for reuse. Hence, that is why we think that it is important to have a set of stringent protocols to follow for segregating the returned medicines. The United States of America (USA), the American Medical Association, and the American Society of Consultant Pharmacists support the practice of medication recycling; however, there are no detailed guidelines on this practice [7].
A total of 29,696 units of oral solid formulation/medicines (89.7\%) were reused over 10 years' period in RIPAS hospital [Table 3]. This is a positive indication whereby pharmacists can play their role in promoting to the doctors and health-care professionals on the importance of returning unused medicines if it is in an oral solid form. Oral solids formed the majority of both the reused (89.7\%) and disposed (74.7\%) medications. In our view, it is easier to return oral solid in blister packaging for single dose as they are widely used for tablets, capsules, and other oral solid formulation. The expiry date would be still clearly intact and can be reused for inpatients at the wards. This is probably the reason why the majority of the returned and disposed medications were in the form of oral solid forms.

Another strategy to reduce medication wastage would be to review the purchasing practices, using limited dose or unit dose dispensing and performing ongoing inventory control and stock rotation. All these activities can be monitor carefully by a Pharmacist in charge. In a study conducted in Malta, whereby medication is supplied to the patient free of charge by the government (based on entitlement criteria), the study have concluded that a strategy to reduce medication wastages is by developing processes which include behavior change theories, such as the theoretical domain framework to significantly impact the four key domains: (1) Practitioner effects, (2) patients effects, (3) political effects, and (4) societal effects [15]. Medication non-adherence is also one of the key barriers hindering resolution of medication wastage.

In Table 4, although the median cost for topical preparations and injections was higher for the reused group, the total costs for both forms of medication were higher for the disposed group [Table 3]. This highlights that some pharmaceutical products such as topical preparations and injections that were disposed incurred a high cost, implying that measures to recycle expensive medications (especially, topical preparations and injections) would help save costs.

However, since this study is due to retrospective data, we could not classify the medicines into their therapeutic classes and the reason for returning the medicine. Both public and health-care professionals need to be educated on the proper storage and prompt return of unused medicines to improve the reusability of unused or patients' medicines.

\section{Study limitation}

One major limitation is the amount of missing data and the consistency of data entry. The eventual destinations of $7.8 \%$ of the returned medications were unrecorded and a total of 879 entries (1.4\%) were removed from the analysis, after applying the exclusion criteria and also to account for suspected data entry errors. Improving data recording would give a better picture on medication wastage in RIPAS hospital, for example, providing the reasons for return apart from not being used anymore. Even though this limitation would potentially affect 
the calculated costs in this study, the relatively high cost of disposed returned medication already suggests that considerable amount of money spent on meditations that were eventually disposed. Another limitation is that data were only collected in one hospital, which may not give a representative picture of the whole health care spending by the Government of Brunei Darussalam.

\section{CONCLUSION}

This study confirms the importance of analyzing the return of unwanted medicines to reduce unnecessary health expenditure. Our study represented a 10 years assessment of returned medicines in a tertiary hospital in Brunei Darussalam. Future study could incorporate reasons of return and the various therapeutic classes of the medicines according to the WHO. This study also highlights that medication recycling and wastage do exist in Brunei Darussalam. If we streamline the recycling protocol across all hospitals and health centers, as well as create more awareness (among the public as well as doctors and health professionals), medication recycling can be a safe and effective approach to reduce medication wastage. Therefore, health-care policymakers, doctors, and health-care professionals should be informed to develop and implement wastage reduction strategies.

\section{ACKNOWLEDGMENT}

The authors would like to acknowledge the Department of Pharmaceutical Services, Ministry of Health, Brunei Darussalam, for allowing us to use their secondary data for this publication.

\section{AUTHORS' CONTRIBUTION}

Author Nurolaini Kifli contributed to the study conception, design, and writing of the manuscript. Author Li Ling Chaw contributed to the acquisition of data, analysis, and interpretation of data. Author Wong Wai See contributed to the acquisition of data as well as to the critical revision of the manuscript.

\section{CONFLICTS OF INTEREST}

All authors have none to declare.

\section{REFERENCES}

1. West LM, Diack L, Cordina M, Stewart D. Applying the delphi technique to define 'medication wastage'. Eur J Hosp Pharm 2015;22:274-9.

2. Kiyingi KS, Lauwo JA. Drugs in the home: Danger and waste. World Health Forum 1993;14:381-4.

3. Ekedahl A, Wergeman L, Rydberg T. Unused drugs in Sweden measured by returns to pharmacies. J Soc Adm Pharm 2003;20:26-31.

4. Heberer T. Occurrence, fate, and removal of pharmaceutical residues in the aquatic environment: A review of recent research data. Toxicol Lett 2002;131:5-17.

5. Kapoor D. Impact of pharmaceutical industries on environment, health and safety. J Crit Rev 2015;2:25-30.

6. World Health Organisation. Health-Care Waste - Fact Sheet. Geneva: World Health Organisation; 2015. Available from: http://www.who.int/ mediacentre/factsheets/fs253/en. [Last accessed on 2018 Mar 08].

7. Consortium YH. Evaluation of the Scale, Causes and Costs of Waste Medicines - Final Report. UK: University of London; 2010.

8. Ministry of Health. Brunei Darussalam, Health Information Booklet 2016, Brunei: Ministry of Health; 2016

9. Ministry of Health. Malaysia, Return Your Medicines Program, Malaysia: P.S. Division; 2013. Available from: https:/www.pharmacy. gov.my/v2/en/content/return-your-medicines-program.html. [Last accessed on 2018 Mar 08]

10. West LM. Medication wastage: The current situation. J Malta Coll Pharm Pract 2015;21:25-8.

11. Pranav V, Prakash N, Vasudeva G. Self medication practice among urban slum dwellers in udupi taluk, Karnataka, India. Int J Pharm Pharm Sci 2017;9:19-23.

12. Toh MR, Chew L. Turning waste medicines to cost savings: A pilot study on the feasibility of medication recycling as a solution to drug wastage. Palliat Med 2017;31:35-41.

13. Hussain M, Naqvi SB, Khan MA, Rizvi M, Alam S, Abbas A, et al. Direct cost of treatment of diabetes mellitus type 2 in Pakistan. Int J Pharm Pharm Sci 2014;6:261-4.

14. The Department of Health, UK. Improving the Use of Medicines for Better Outcomes and Reduced Waste: An Action Plan. UK: Department of Health UK London; 2012.

15. West LM, Diack L, Cordina M, Stewart D. A focus group based study of the perspectives of the Maltese population and healthcare professionals on medication wastage. Int J Clin Pharm 2016;38:1241-9.

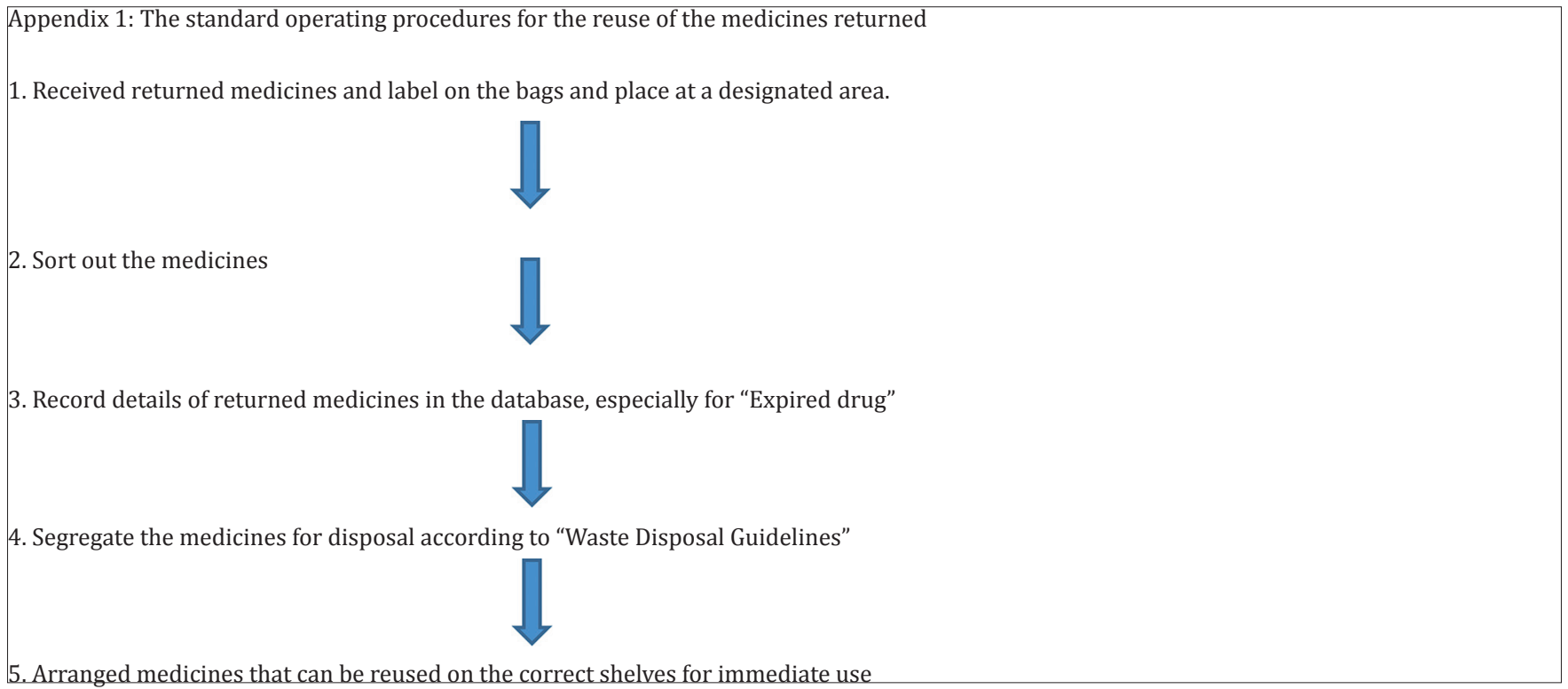

